CZASOPISMO INŻYNIERII LĄDOWEJ, ŚRODOWISKA I ARCHITEKTURY JOURNAL OF CIVIL ENGINEERING, ENVIRONMENT AND ARCHITECTURE JCEEA, t. XXXIII, z. 63 (1/II/16), styczeń-marzec 2016, s. 137-144

\author{
Marcin BILSKI ${ }^{1}$ \\ Mieczysław SŁOWIK ${ }^{2}$ \\ Marta MIELCZAREK ${ }^{3}$
}

\title{
BADANIE ZJAWISKA RELAKSACJI NAPRĘ̇̇EŃ ZACHODZĄCEGO W ASFALTACH DROGOWYCH PODDANYCH ROZCIĄGANIU W NISKIEJ TEMPERATURZE
}

\begin{abstract}
W artykule przedstawiono rezultaty badań oraz analizę metody badawczej opracowanej przez autorów pracy do obserwacji zjawiska relaksacji naprężeń w lepiszczach asfaltowych w niskiej temperaturze. W badaniach wykorzystano asfalty drogowe 20/30, 35/50 i 50/70. Obserwacji zjawiska relaksacji naprężeń dokonano w warunkach stałego odkształcenia próbki spowodowanego oddziaływaniem siły normalnej (rozciągającej). W badaniach wykorzystano duktylometr wyposażony w siłomierze oraz łaźnię wodną wypełnioną cieczą o temperaturze $-16^{\circ} \mathrm{C}$. W celu określenia dokładności metody pomiarowej opracowanej przez autorów pracy przeprowadzono analizę statystyczną uzyskanych wyników, na podstawie której stwierdzono, że zastosowana metoda może być wykorzystywana do obserwacji zjawiska relaksacji naprężeń w niskiej temperaturze. Wartości naprężeń obliczono na podstawie oznaczonych wartości siły rozciągającej. Zaobserwowano, że asfalty o większych wartościach penetracji odznaczają się w niskiej temperaturze lepszą zdolnością do relaksacji naprężeń, a proces ten przy stałym odkształceniu następuje szybciej. Dodatkowo przeprowadzono analizę porównawczą wyników oznaczeń modułu sztywności w temperaturze $-16^{\circ} \mathrm{C}$ uzyskanych na podstawie opracowanej metody badawczej z wykorzystaniem duktylometru oraz oznaczeń przeprowadzonych w reometrze zginanej belki (BBR) i reometrze dynamicznego ścinania (DSR). Wartości modułu sztywności w duktylometrze oznaczono na podstawie testu rozciągania, podczas którego występuje zbliżona do liniowej zależność naprężeń w funkcji odkształceń. Stwierdzono rozbieżności pomiędzy wynikami oznaczania modułu sztywności $\mathrm{z}$ użyciem trzech metod pomiarowych opisanych w niniejszej pracy.
\end{abstract}

Słowa kluczowe: lepiszcze asfaltowe, relaksacja w niskiej temperaturze, próba rozciągania, naprężenie, odkształcenie

\footnotetext{
${ }^{1}$ Autor do korespondencji/corresponding author: Marcin Bilski, Politechnika Poznańska, Instytut Inżynierii Lądowej, ul. Piotrowo 5, 61-138 Poznań, 61-665-3485, marcin.bilski@ put.poznan.pl

2 Mieczysław Słowik, Politechnika Poznańska, Instytut Inżynierii Lądowej, ul. Piotrowo 5, 61-138 Poznań, 61-665-2478, mieczyslaw.slowik@put.poznan.pl

${ }^{3}$ Marta Mielczarek, Politechnika Poznańska, Instytut Inżynierii Lądowej, ul. Piotrowo 5, 61-138 Poznań, 61-665-3487, marta.mielczarek@ put.poznan.pl
} 


\section{Wprowadzenie}

Opisu właściwości reologicznych lepiszczy asfaltowych można dokonać m. in. na podstawie wyników badania zjawiska relaksacji naprężeń. O zjawisku relaksacji naprężeń mówimy w sytuacji, kiedy w próbce materiału został wywołany stan odkształcenia (np. w wyniku rozciągania), a naprężenia zmniejszają się w czasie przy stałym odkształceniu. Czynnikiem wpływającym na intensywność opisywanego zjawiska jest temperatura. Lepiszcze asfaltowe podczas ochładzania ulega usztywnieniu, co w bardzo niskiej temperaturze skutkuje jego podatnością na pękanie. W celu zminimalizowania negatywnego wpływu niskiej temperatury na stan nawierzchni drogowej należy dobierać lepiszcze asfaltowe z uwzględnieniem warstwy, w której ma być zastosowane oraz strefy klimatycznej, w jakiej ma pracować nawierzchnia. Z punktu widzenia odporności asfaltowej nawierzchni drogowej na powstawanie spękań niskotemperaturowych pożądaną cechą lepiszcza asfaltowego jest zdolność do szybkiej relaksacji naprężeń. Lepiszcza asfaltowe odznaczające się małą zdolnością do relaksacji są bardziej podatne na pękanie $w$ niskiej temperaturze ze względu na powstawanie naprężeń rozciągających indukowanych termicznie $[4,5,6]$.

W Stanach Zjednoczonych w ramach programu SHRP opracowano m. in. metodykę oznaczania właściwości lepiszczy asfaltowych w ujemnych temperaturach - Bending Beam Rheometer oraz Direct Tension Test. Pierwszym z urządzeń jest reometr zginanej belki (BBR) wykorzystywany do oceny usztywnienia próbki lepiszcza asfaltowego (oznaczania modułu sztywności) oraz do badania zjawiska pełzania przy obciążeniu statycznym i nawrotu po odciążeniu. Drugim z urządzeń jest aparat bezpośredniego rozciągania (DTT), w którym określana jest zdolność lepiszcza do wydłużenia tzn. oznacza się odkształcenie będące stosunkiem wydłużenia próbki w chwili zerwania do jej długości początkowej. Natomiast reometr dynamicznego ścinania (DSR - Dynamic Shear Rheometer) jest wykorzystywany przede wszystkim do oznaczania złożonych właściwości reologicznych lepiszcza asfaltowego $(\mathrm{m}$. in. zespolonego modułu ścinania i kąta przesunięcia fazowego) w różnych zakresach częstotliwości i temperatury. Bardzo duża uniwersalność reometru DSR pozwala na jego wykorzystanie do oceny właściwości niskotemperaturowych lepiszczy asfaltowych. Parametry reologiczne takie, jak moduł sztywności czy parametr „m” oznaczane w reometrze BBR można poprzez modelowanie matematyczne skorelować z wynikami uzyskiwanymi w reometrze DSR [1, 2, 3, 5].

\section{Cel badań}

Autorzy pracy opierając się na założeniach metody Direct Tension Test (DTT) wykorzystali duktylometr umożliwiający pomiar siły rozciągającej do oceny właściwości niskotemperaturowych asfaltów drogowych. Celem badań było poznanie zjawiska relaksacji naprężeń jakie zachodzi w asfaltach drogo- 
wych w wyniku wywołania stanu odkształcenia poprzez ich rozciągnięcie w niskiej temperaturze. Wyznaczono również wartości modułu sztywności w temperaturze $-16^{\circ} \mathrm{C}$, które porównano z wynikami uzyskanymi z zastosowaniem reometrów BBR i DSR.

\section{Metoda badawcza}

W metodzie badawczej opracowanej przez autorów pracy wykorzystano aparaturę pomiarową stosowaną $\mathrm{w}$ teście rozciągania próbek asfaltowych wg PN-EN 13589:2011 Asfalty i lepiszcza asfaltowe - Oznaczanie sity rozciagania asfaltów modyfikowanych, metoda $z$ duktylometrem. Badaniom poddano trzy asfalty drogowe: 20/30, 35/50 i 50/70. Zastosowano następujące warunki pomiaru:

- temperatura: $-16^{\circ} \mathrm{C} \pm 0,2^{\circ} \mathrm{C}$,

- czas termostatowania próbek asfaltowych w łaźni duktylometru: 30 min,

- prędkość rozciągania: $1 \mathrm{~mm} / \mathrm{min}$,

- zakończenie procedury rozciągania: w chwili osiągnięcia wartości siły rozciągającej równej $50 \mathrm{~N}$,

- czas zapisu siły rozciągającej w warunkach stałego odkształcenia: 20 min.

Badanie realizowano $\mathrm{w}$ dwóch etapach: $\mathrm{w}$ pierwszym oznaczano moduł sztywności na podstawie zależności naprężenia od odkształcenia, natomiast w drugim obserwowano zjawisko relaksacji naprężeń.

\section{Wyniki badań}

W tabeli 1 zestawiono podstawowe właściwości asfaltów drogowych wykorzystanych $\mathrm{w}$ przeprowadzonych badaniach, tj. temperatura mięknienia wg PN-EN 1427:2015-08, penetracja w temperaturze $25^{\circ} \mathrm{C}$ i indeks penetracji wyznaczone wg PN-EN 1426:2015-08.

Tabela 1. Podstawowe właściwości badanych asfaltów

Table 1. The basic properties of the investigated road bitumens

\begin{tabular}{|c|c|c|c|}
\hline Asfalt & $\mathbf{2 0 / 3 0}$ & $\mathbf{3 5} / \mathbf{5 0}$ & $\mathbf{5 0 / 7 0}$ \\
\hline Temperatura mięknienia , ${ }^{\circ} \mathrm{C}$ & $63,6 \pm 0,2$ & $55,9 \pm 0,5$ & $51,6 \pm 0,2$ \\
\hline Penetracja w $25^{\circ} \mathrm{C}, \mathrm{mm} / 10$ & $25,6 \pm 0,5$ & $40,8 \pm 0,3$ & $55,9 \pm 0,7$ \\
\hline Indeks Penetracji & $0,21 \pm 0,04$ & $-0,30 \pm 0,09$ & $-0,56 \pm 0,04$ \\
\hline
\end{tabular}

Na rysunku 1 przedstawiono przykładowe wyniki oznaczania siły rozciągającej $\mathrm{w}$ funkcji czasu $\mathrm{w}$ temperaturze $-16^{\circ} \mathrm{C}$ pomierzonej podczas rozciągania próbek wykonanych z asfaltu 35/50 aż do osiągnięcia wartości siły równej $50 \mathrm{~N}$. Następnie, po zatrzymaniu napędu duktylometru kontynuowano pomiar siły przez 20 min. Wykonano niezależne badania na czterech próbkach każdego 
z zastosowanych asfaltów. W tabeli 2 przedstawiono wartości parametrów statystycznych obliczonych na podstawie pomiaru siły rozciągającej $\mathrm{w}$ warunkach stałego odkształcenia: na początku $(t=0 \mathrm{~s}-$ zakończenie procedury rozciągania), a także w połowie $(t=600 \mathrm{~s})$ i na końcu $(t=1200 \mathrm{~s})$ okresu obserwacji zjawiska relaksacji zachodzącego $\mathrm{w}$ badanych asfaltach drogowych.

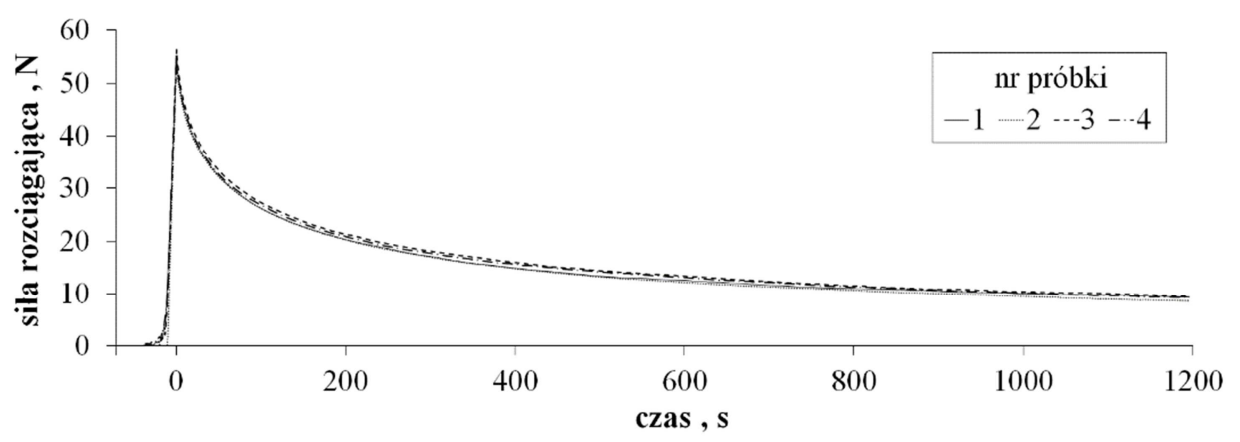

Rys. 1. Wartości siły rozciągającej w funkcji czasu dla próbek asfaltu $35 / 50 \mathrm{w}$ temperaturze $-16^{\circ} \mathrm{C}$ Fig. 1. Values of tensile force as a function of time determined for $35 / 50$ penetration grade bitumen specimens at $-16^{\circ} \mathrm{C}$

Tabela 2. Parametry statystyczne siły rozciągającej występującej w próbkach badanych asfaltów w temperaturze $-16^{\circ} \mathrm{C}$

Table 2. Statistical parameters of the tensile force occurring in tested asphalt binders at $-16^{\circ} \mathrm{C}$

\begin{tabular}{|c|c|c|c|c|c|c|c|c|c|}
\hline Czas & \multicolumn{3}{|c|}{$\boldsymbol{t = 0 ~ s}$} & \multicolumn{3}{c|}{$\boldsymbol{t}=\mathbf{6 0 0} \mathbf{s}$} & \multicolumn{3}{c|}{$\boldsymbol{t}=1200 \mathrm{~s}$} \\
\hline Asfalt & $20 / 30$ & $35 / 50$ & $50 / 70$ & $20 / 30$ & $35 / 50$ & $50 / 70$ & $20 / 30$ & $35 / 50$ & $50 / 70$ \\
\hline $\bar{F}, \mathrm{~N}$ & 55,40 & 55,03 & 54,14 & 22,07 & 12,71 & 12,12 & 17,19 & 9,08 & 8,70 \\
\hline$s_{x}, \mathrm{~N}$ & 0,479 & 0,894 & 0,553 & 0,365 & 0,530 & 0,081 & 0,517 & 0,374 & 0,181 \\
\hline$v, \%$ & 0,9 & 1,6 & 1,0 & 1,7 & 4,2 & 0,7 & 3,0 & 4,1 & 2,1 \\
\hline$U(x), \mathrm{N}$ & 0,56 & 1,05 & 0,65 & 0,43 & 0,62 & 0,10 & 0,61 & 0,44 & 0,21 \\
\hline$\frac{U(x) \cdot 100}{\bar{F}}, \%$ & 1,0 & 1,9 & 1,2 & 1,9 & 4,9 & 0,8 & 3,5 & 4,8 & 2,4 \\
\hline
\end{tabular}

gdzie: $\bar{F}$ - wartość średnia, $s_{x}$ - odchylenie standardowe, $v$ - współczynnik zmienności, $U(x)$ - niepewność rozszerzona dla $\alpha=0,05$.

Wykorzystując średnie wartości siły rozciągającej wyznaczono średnie wartości naprężeń rozciągających w badanych asfaltach według wzoru 1.

$$
\sigma=\frac{\bar{F}}{A}, \mathrm{~Pa}
$$

gdzie: $\bar{F}$ - średnia wartość siły rozciągającej, N,

$A$ - pole powierzchni przekroju próbki, $\mathrm{m}^{2}$. 
Ze względu na małe odkształcenia próbek przyjęto założenie dotyczące niezmienności przekroju poprzecznego, stąd $A=10^{-4} \mathrm{~m}^{2}$ (wysokość i szerokość równa $1 \mathrm{~cm}$ ). Wykorzystując zbliżoną do liniowej zależność naprężenia w funkcji odkształcenia podczas rozciągania próbki asfaltu obliczono wartości modułu sztywności dla badanych lepiszczy wg wzoru 2.

$$
S=\frac{\sigma_{\max }}{\varepsilon_{\max }}, \mathrm{Pa}
$$

gdzie: $\sigma_{\max }-$ maksymalna wartość naprężeń rozciągających, $\mathrm{Pa}$, ru 3 .

$\varepsilon_{\max }$ - maksymalna wartość odkształcenia względnego obliczona wg wzo-

$$
\varepsilon_{\max }=\frac{\Delta l_{\max }}{l}
$$

gdzie: $\Delta l_{\max }$ - maksymalna wartość wydłużenia próbki w chwili osiągnięcia siły równej $50 \mathrm{~N}, \mathrm{~mm}$,

$l$ - początkowa długość próbki równa $30 \mathrm{~mm}$.

Wartość $\Delta l_{\max }$ wyznaczono z uwzględnieniem nachylenia prostoliniowej części wykresu zależności naprężenia $\mathrm{w}$ funkcji odkształcenia podczas rozciągania próbek, pomijając część nieliniową, która występuje w pierwszej fazie procesu rozciągania.

W tabeli 3 przedstawiono wartości maksymalnego wydłużenia próbki, dla którego obliczono wartości maksymalnego odkształcenia oraz podano wartości maksymalnych naprężeń. Zamieszczono również wartości parametrów charakteryzujących właściwości badanych asfaltów $\mathrm{w}$ temperaturze $-16^{\circ} \mathrm{C}$ takich jak moduł sztywności $S$ oznaczony w teście rozciągania w duktylometrze oraz w reometrze BBR dla czasu obciążenia równego $0,5 \mathrm{~s}$ i $60 \mathrm{~s}$, a także zespolony moduł ścinania $\left|G^{*}\right|$ oznaczony $\mathrm{w}$ reometrze DSR przy prędkości kątowej $\omega=10 \mathrm{rad} / \mathrm{s}$.

Tabela 3. Zestawienie wyników badań asfaltów uzyskanych w teście rozciągania oraz w reometrach BBR i DSR w temperaturze $-16^{\circ} \mathrm{C}$

Table 3. Test results of bitumens obtained from the tensile test, BBR and DSR rheometers at $-16^{\circ} \mathrm{C}$

\begin{tabular}{|c|c|c|c|c|c|c|c|}
\cline { 2 - 8 } \multicolumn{1}{c|}{} & \multicolumn{6}{|c|}{ Test rozciągania w duktylometrze } & \multicolumn{2}{c|}{ Reometr BBR } & Reometr DSR \\
\hline Asfalt & $\begin{array}{c}\Delta l_{\max }, \\
\mathrm{mm}\end{array}$ & $\varepsilon_{\max }$ & $\begin{array}{c}\sigma_{\max }, \\
\mathrm{kPa}\end{array}$ & $\begin{array}{c}S, \\
\mathrm{MPa}\end{array}$ & $\begin{array}{c}S_{(0,5 s)}, \\
\mathrm{MPa}\end{array}$ & $\begin{array}{c}S_{(60)}, \\
\mathrm{MPa}\end{array}$ & $\begin{array}{c}\left|G^{*}\right| \mathrm{dla} \\
\omega=10 \mathrm{rad} / \mathrm{s}, \\
\mathrm{MPa}\end{array}$ \\
\hline $20 / 30$ & 0,196 & 0,0065 & 554,0 & 852,3 & 683,1 & 207,4 & 402,6 \\
\hline $35 / 50$ & 0,203 & 0,0068 & 550,3 & 809,3 & 582,1 & 149,7 & 366,7 \\
\hline $50 / 70$ & 0,217 & 0,0072 & 541,4 & 751,4 & 558,3 & 127,6 & 323,0 \\
\hline
\end{tabular}


Na rysunku 2 przedstawiono krzywe relaksacji naprężeń rozciągających (obliczonych według wzoru 1) w warunkach stałego odkształcenia próbek asfaltów drogowych $20 / 30,35 / 50$ i 50/70 w temperaturze $-16^{\circ} \mathrm{C}$.

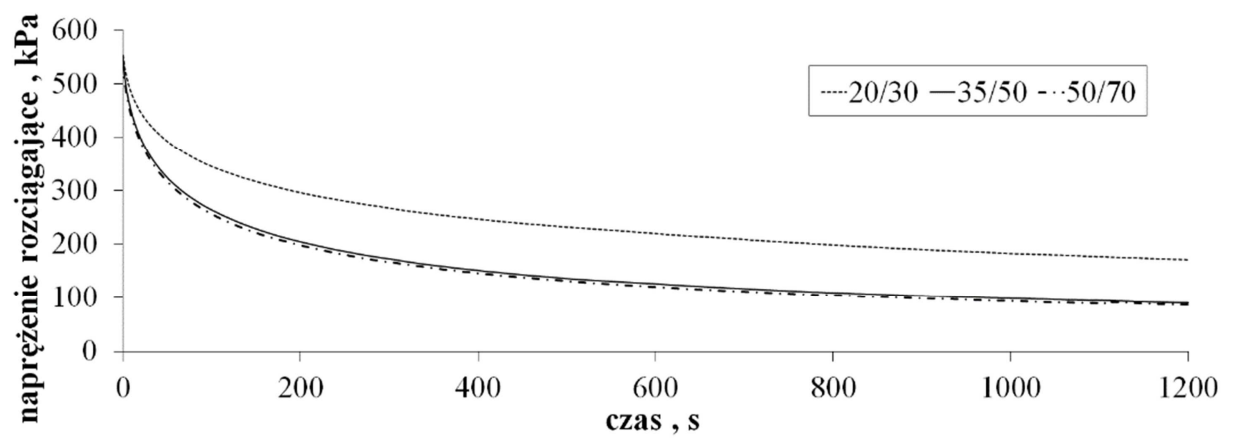

Rys. 2. Krzywe relaksacji naprężeń w warunkach stałego odkształcenia próbek asfaltów drogowych badanych w temperaturze $-16^{\circ} \mathrm{C}$

Fig. 2. Relaxation curves obtained under constant strain conditions for specimens of road bitumen investigated at $-16^{\circ} \mathrm{C}$

\section{Dyskusja}

W celu określenia dokładności autorskiej metody pomiarowej opisanej w pracy wykonano analizę statystyczną (tabela 2) dla wartości naprężeń w warunkach stałego odkształcenia próbek asfaltów w temperaturze $-16^{\circ} \mathrm{C}$ w chwili $t$ okresu obserwacji zjawiska relaksacji naprężeń równej 0 s, $600 \mathrm{~s} \mathrm{i} 1200 \mathrm{~s}$. Największe zróżnicowanie $\mathrm{w}$ wartościach siły rozciągającej badanych asfaltów stwierdzono $\mathrm{w}$ połowie okresu obserwacji zjawiska relaksacji naprężeń (wartości współczynnika zmienności wynoszą od $0,7 \%$ do 4,2\%). Wartości niepewności rozszerzonej $U(x)$ obliczono z uwzględnieniem wartości niepewności standardowej $u(x)$, wzorcowania $u_{d}(x)$ i eksperymentatora $u_{e}(x)$, a współczynnik rozszerzenia $k$ przyjęto dla poziomu istotności równego $\alpha=0,05$ i trzech stopni swobody. Niepewność pomiaru dla badanych asfaltów wynosi od $0,10 \mathrm{~N}$ do $1,05 \mathrm{~N}$, co świadczy o zadowalającej dokładności opracowanej metody, tzn. oznaczana wartość siły rozciągającej zawiera się z 95\% prawdopodobieństwem W przedziale $\pm 1 \mathrm{~N}$ od wartości średniej. W przypadku oznaczania wartości maksymalnej siły rozciągającej przyjmuje się za akceptowalną wartość niepewności rozszerzonej $U(x)$ równą maksymalnie $10 \%$ wartości średniej. W opracowanej przez autorów pracy metodzie badania zjawiska relaksacji naprężeń wartość niepewności $U(x)$ stanowi maksymalnie 4,9\% średniej wartości siły rozciągającej. Na podstawie wyników przedstawionych w tabeli 2 stwierdzono, że metoda badawcza opracowana przez autorów pracy może być wykorzystywana do obserwacji zjawiska relaksacji naprężeń w ujemnej temperaturze. 
W tabeli 3 zestawiono wartości modułu sztywności oznaczone dla badanych asfaltów w teście rozciągania w duktylometrze oraz w reometrach BBR i DSR w temperaturze $-16^{\circ} \mathrm{C}$. Standardowo moduł sztywności w reometrze BBR oznacza się na podstawie ugięcia asfaltowej belki pomierzonego po $60 \mathrm{~s}$ obciążania pionową siłą statyczną. Założono, że w chwili $t=0,5 \mathrm{~s}$ występują jedynie odkształcenia sprężyste, a dla $t>0,5 \mathrm{~s}$ wartości odkształceń są związane ze zjawiskiem pełzania lepiszcza asfaltowego pod obciążeniem statycznym. W celu porównania uzyskanych wyników z różnych metod badawczych wartości modułu sztywności oznaczono w reometrze BBR również po czasie obciążenia równym $0,5 \mathrm{~s}$. Wartości zespolonego modułu ścinania $\left|G^{*}\right|$ oznaczonego w reometrze DSR w temperaturze $-16^{\circ} \mathrm{C}$ stanowią stosunek maksymalnych naprężeń ścinających do największych odkształceń. Stwierdzono rozbieżności pomiędzy wartościami modułu sztywności oznaczonymi w duktylometrze i reometrach BBR i DSR. Rozbieżności w wartościach modułu sztywności są związane z faktem ich wyznaczania z użyciem różnych metod badawczych, tzn. w teście rozciągania w duktylometrze występują naprężenia normalne (rozciągające), w reometrze BBR naprężenia rozciągające przy zginaniu a w reometrze DSR naprężenia styczne (ścinające).

Analizując rysunek 2 można zaobserwować, że im asfalt jest twardszy (ma mniejszą wartość penetracji $\mathrm{w} 25^{\circ} \mathrm{C}$ ) tym wolniej zachodzi zjawisko relaksacji naprężeń w próbce, a jego intensywność jest mniejsza. Nie zanotowano wyraźnych różnic w zdolności do relaksacji naprężeń dla asfaltów 35/50 i 50/70 co można tłumaczyć faktem, że są to lepiszcza o podobnym typie reologicznym (koloidalnym) i porównywalnej zawartości części olejowej, różniących te asfalty od asfaltu 20/30. Analizując uzyskane wyniki stwierdzono, że potwierdzają one powszechnie znaną cechę asfaltów, tzn. im twardszy asfalt (mniejsza wartość penetracji $\mathrm{w} 25^{\circ} \mathrm{C}$ ) tym większa jego sztywność w niskiej temperaturze. Stwierdzono również, że relaksacja naprężeń w takim lepiszczu zachodzi wolniej, co skutkuje jego większą podatnością na spękania niskotemperaturowe.

\section{Wnioski}

- Opracowana przez autorów pracy metoda badawcza może być wykorzystywana do analizy zjawiska relaksacji naprężeń w warunkach stałego odkształcenia w próbkach asfaltowych w ujemnych temperaturach.

- Niepewność pomiarowa obliczona z 95\% prawdopodobieństwem dla opracowanej metody wynosi $\pm 1 \mathrm{~N}$, co można uznać za korzystne z punktu widzenia precyzji pomiarów.

- W każdej z trzech metod oznaczania modułu sztywności poddanych analizie w pracy, stan naprężenia w próbce lepiszcza asfaltowego jest wywoływany w inny sposób, co może być powodem rozbieżności uzyskanych wyników.

- Asfalty o większej wartości penetracji w temperaturze $25^{\circ} \mathrm{C}$ odznaczają się zdolnością do szybszej relaksacji naprężeń w niskiej temperaturze, a więc można je uznać za bardziej odporne na powstawanie spękań indukowanych termicznie. 


\section{Literatura}

[1] Błażejowski K., Olszacki J., Peciakowski H.: Poradnik asfaltowy, ORLEN Asfalt, Płock 2014.

[2] Farrar M., Sui C., Salmans S., Qin Q.: Determining the Low-Temperature Rheological Properties of Asphalt Binder Using a Dynamic Shear Rheometer (DSR), Western Research Institute, Laramie 2015.

[3] Ho S., Zanzotto L.: The low temperature properties of conventional and modified asphalt binders evaluated by the failure energy and secant modulus from direct tension tests, Materials and Structures 38 (275), 2005, pp. 137-143.

[4] Pszczoła M., 2006. Spękania niskotemperaturowe warstw asfaltowych nawierzchni, Drogi i Mosty 3/2006, s. 76-110.

[5] Słowik M.: Wybrane zagadnienia lepkosprężystości drogowych asfaltów modyfikowanych zawierających elastomer SBS, Wydawnictwo Politechniki Poznańskiej, Poznań 2013.

[6] Sybilski D.: Nawierzchnie asfaltowe w trudnych warunkach naturalnych, I Lubelska Konferencja Techniki Drogowej, Konferencja PKD, Lublin 2014.

\section{INVESTIGATION OF RELAXATION PHENOMENON OCCURRED IN ROAD BITUMEN SUBJECTED TO STRETCH AT LOW TEMPERATURE}

\section{S u m m a r y}

Results of investigation and analysis of the testing method discovered by authors of the paper to observe the relaxation phenomenon occurred in road bitumen subjected to stretch at low temperature in the article are presented. In research program were used 20/30, 35/50 and 50/70 penetration grade road bitumens. The relaxation phenomenon of the asphalt binder specimens was observed under constant strain conditions which was caused by the tensile force. In the study a ductilometer equipped in force sensors and water bath filled by liquid of $-16^{\circ} \mathrm{C}$ were used. In order to determine the accuracy of the test method discovered by the authors of the paper a statistical analysis was conducted. The results showed that the applied test method can be used to observe the relaxation phenomenon at low temperatures. Values of stress were calculated on the basis of the determined values of tensile force. It was observed that asphalt binders with a high penetration values have more ability to relaxation and that process occurs more rapidly. In addition, a comparative analysis of determined values of the stiffness modulus at $-16^{\circ} \mathrm{C}$ was done for applied test method using ductilometer, Bending Beam Rheometer (BBR) and Dynamic Shear Rheometer (DSR). During the tensile test in ductilometer the stress-strain curve was similar to linear which allowed to determine values of stiffness modulus. Divergence between the results of the determination of stiffness modulus using three measurement methods were found in this paper.

Keywords: asphalt binder, relaxation at low-temperature, tensile test, stress, strain

Przestano do redakcji: 07.06.2016 r.

Przyjęto do druku: 30.06.2016 r.

DOI: $10.7862 /$ rb.2016.69 